\title{
Dieulafoy's lesions of the rectum: A rare cause of lower gastrointestinal bleeding
}

\author{
Robert Enns MD FRCP
}

\begin{abstract}
R Enns. Dieulafoy's lesions of the rectum: A rare cause of lower gastrointestinal bleeding. Can J Gastroenterol 2001;15(8):541-544. Dieulafoy's lesions located outside of the stomach are rare occurrences. Lesions found within the colon typically present with painless, massive hematochezia (ie, greater than $5 \mathrm{U}$ ). If they can be accurately located, endoscopic therapy in the form of adrenaline injection, sclerotherapy or cauterization appears to have long term success. The present report details the case of a 72-year-old man who presented with massive hematochezia and who was discovered to have a Dieulafoy's lesion within the rectum. The lesion was located just distal to a previous surgical anastomosis, and was successfully treated with adrenaline and electrocautery. Colonic Dieulafoy's lesions are rare but should always be considered in the differential diagnosis of massive hematochezia, because endoscopic therapy appears to result in complete cessation of bleeding.
\end{abstract}

\section{Lésions rectales de Dieulafoy : Rare cause de saignement gastro-intestinal}

RÉSUMÉ : Les lésions de Dieulafoy situées à l'extérieur de l'estomac sont des phénomènes rares. Les lésions observées au niveau du côlon s'accompagnent généralement de selles sanglantes indolores (c.-à-d. plus de $5 \mathrm{U})$. S'il est possible de les localiser avec précision, le traitement endoscopique par injection d'adrénaline, sclérothérapie ou cautérisation semble réussir à long terme. On présente ici le cas d'un homme de 72 ans qui a présenté des selles sanglantes importantes et chez qui l'on a décelé une lésion de Dieulafoy au niveau rectal. La lésion était située à la portion distale d'une anastomose chirurgicale antérieure et a été traitée avec succès par adrénaline et cautérisation. Les lésions de Dieulafoy du côlon sont rares, mais doivent toujours être envisagées dans le diagnostic différentiel dans les cas de selles sanglantes importantes, parce que le traitement endoscopique semble entraîner un arrêt complet du saignement.

Key Words: Bleeding; Colon; Dieulafoy

M assive hematochezia typically occurs in elderly patients (average 60 years old) (1), carries a mortality rate of up to $30 \%(2-5)$ and accounts for about $0.7 \%$ of all discharges from hospital (6). Although there are many possible causes of lower gastrointestinal bleeding (7), the etiology of massive lower gastrointestinal bleeding is much more limited. The most common cause of massive lower gastrointestinal bleeding is diverticulosis, which accounts for approximately $30 \%$ to $40 \%$ of all cases $(7-13)$. Although arteriovenous malformations are responsible for only $2 \%$ of all lower gastrointestinal bleeding (7), they account for $15 \%$ to $30 \%$ of massive gastrointestinal hemorrhage $(8,9,11-19)$. Other causes of massive lower gastrointestinal bleeding include (in order of decreasing frequency)

Division of Gastroenterology, Department of Medicine, St Paul's Hospital, University of British Columbia, Vancouver, British Columbia

Correspondence: Dr Robert Enns, 300-1144 Burrard Street, Vancouver, British Columbia V6K 2A5. Telephone 604-688-7017, fax604-689-2004,e-mail renns@interchange.ubc.ca

Received for publication June 23, 2000. Accepted November 10, 2000 

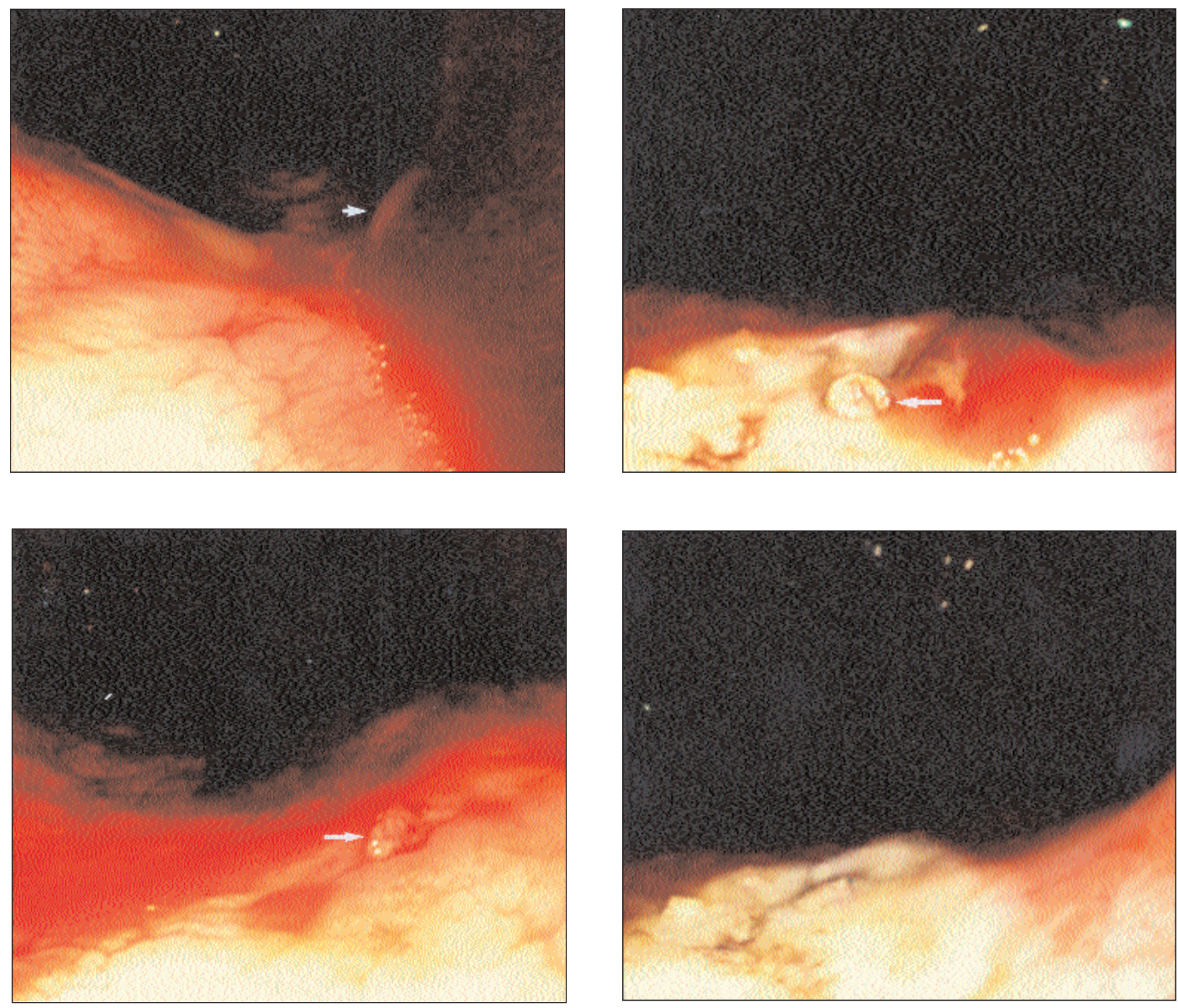

Figure 1) Bright red spurting was initially seen (top left). After adrenaline injection, the bleeding ceased, and the lesion (bottom left) could be more clearly visualized as an isolated vessel within the rectum. Electrocautery was performed (top right) with initial blanching and subsequent obliteration (bottom right) of the vessel

cancer, polyps, inflammatory bowel disease and ischemia.

Dieulafoy's lesion, also known as 'caliber-persistent artery of the stomach', was originally reported by Gallard (20) and subsequently was described further by the French surgeon Dieulafoy (21) in 1889. It is usually a gastric lesion found in the proximal one-third of the stomach, near the eosophagogastric junction. Histologically, it is defined as a thickwalled arterial vessel surrounded by a very shallow ulcer (22). The presentation is relatively uniform, with patients presenting with massive upper gastrointestinal hemorrhage (sometimes recurrent) and melena. The lesion is uncommon ( $1 \%$ to $2 \%$ of upper gastrointestinal hemorrhages) (23-25) and sometimes difficult to locate endoscopically. Once located (usually in the body or fundus of the stomach), endoscopic therapy is the treatment of choice. Originally confined to the stomach, Dieulafoy's lesions have now rarely been described in the esophagus (23), small bowel and colon (26-29). We describe a case of massive lower gastrointestinal hemorrhage secondary to a rectal Dieulafoy's lesion, which was treated successfully endoscopically.

\section{CASE PRESENTATION}

A 72-year-old white man presented to hospital with shortness of breath. He had an extensive cardiac history, and had been managed on amiodarone, nitroglycerin and furosemide. Investigations on his shortness of breath were extensive and included computerized tomography of his chest, bronchoscopy and subsequent open-lung biopsy. Bronchiolitis obliterans with organizing pneumonia and interstitial fibrosis (likely secondary to amiodarone) was diagnosed. Intravenous steroids were administered with some improvement in his respiratory parameters. Surgical history 
TABLE 1

Case summaries of Dieulafoy's lesions of the colon

\begin{tabular}{|c|c|c|c|c|}
\hline Author (reference) & Age (years), sex & Bleeding site (n) & Diagnosis (n) & Treatment (n) \\
\hline Barbier et al (31) & 59, male; 63 , male; 74 , male & Right colon & Surgical (2); endoscopic (1) & Surgical resection (3) \\
\hline Richards et al (39) & 60 , male & Right colon & Angiography & Surgical resection \\
\hline Schmitt et al (40) & 21, female & Right colon & Endoscopic & $\begin{array}{l}\text { Endoscopic (adrenaline } \\
\text { and athoxysklerol) }\end{array}$ \\
\hline Schmid et al (41) & 69 , male & Right colon & Endoscopic & Endoscopic polypectomy (cauterized) \\
\hline Ma et al (42) & 60 , male & Right colon & Radiological (angiogram) & Surgical resection \\
\hline $\begin{array}{l}\text { Franko and } \\
\text { Chadavoyne (33) }\end{array}$ & 20, male & Rectum & Endoscopic & $\begin{array}{l}\text { Failed adrenaline and } \\
\text { heater probe; surgical (oversewn) }\end{array}$ \\
\hline Abdulian et al (32) & 43, male & Rectum & Endoscopic & $\begin{array}{l}\text { Endoscopic (adrenaline and } \\
\text { alcohol and tetradocyl sulphate) }\end{array}$ \\
\hline Tooson et al (36) & 5, female & Rectum & $\begin{array}{c}\text { Endoscopic } \\
(\text { colonoscopy } \times 3)\end{array}$ & $\begin{array}{c}\text { Endoscopic (adrenaline } \\
\text { and heater probe) }\end{array}$ \\
\hline Dy et al (26) & $\begin{array}{l}\text { 65, female; } 70, \text { male; } 73 \text {, female; } \\
\text { 76, female; } 94 \text {, female }\end{array}$ & $\begin{array}{l}\text { Right colon (4); } \\
\text { transverse colon (1) }\end{array}$ & Endoscopic & $\begin{array}{l}\text { Endoscopic (adrenaline } \\
\text { and heater probe) }\end{array}$ \\
\hline Abdelmalek et al (35) & 76 , male & Rectum & Endoscopic & $\begin{array}{c}\text { Endoscopic (adrenaline and } \\
\text { heater probe), then surgical (oversewn) }\end{array}$ \\
\hline Meister et al (27) & $\begin{array}{l}\text { 5, female; } 7 \text {, male; } 67 \text {, male; } \\
\text { 74, male; } 77 \text {, male }\end{array}$ & Rectum & Endoscopic & $\begin{array}{l}\text { Endoscopic (adrenaline } \\
\text { and heater probe) }\end{array}$ \\
\hline Eguchi et al (37) & 78, male & Rectum & Red blood cell scintigraphy & Surgical (oversewn) \\
\hline
\end{tabular}

included a sigmoid colon resection for diverticular disease. His creatinine was also noted to be elevated to $205 \mu \mathrm{mol} / \mathrm{L}$ (normal less than $100 \mu \mathrm{mol} / \mathrm{L}$ ), and a renal biopsy did not demonstrate any evidence of vasculitis. Three weeks after admission, passage of bloody stools was noted. His hemoglobin decreased from $104 \mathrm{~g} / \mathrm{L}$ to $92 \mathrm{~g} / \mathrm{L}$, but he did not develop any orthostatic changes. Although he was transfused with $2 \mathrm{U}$ of blood that evening, his hemoglobin fell further the following day to $84 \mathrm{~g} / \mathrm{L}$. Although he had no upper gastrointestinal symptoms, an upper endoscopy was performed, which demonstrated superficial esophageal ulcers. These were biopsied and proved to be herpes simplex esophagitis. Because no blood was visualized in the upper intestinal tract, a colonoscopy was performed immediately after the upper endoscopy. This demonstrated dark blood throughout the colon (with the surgical anastamosis visible at $20 \mathrm{~cm}$ from the anal verge) but no evidence of active bleeding. There was no blood within the terminal ileum.

Because there was no evidence of active bleeding, the patient was managed supportively. The following day, rectal bleeding recurred; this time it appeared bright red in colour. A total of $8 \mathrm{U}$ of packed red blood cells were transfused. A repeat unprepped colonoscopy was performed. Initially, visualization was challenging within the rectum, because bright red blood coated the entire region up to the surgical anastamosis. Careful irrigation showed what appeared to be a 'spurting' site of bleeding $5 \mathrm{~cm}$ distal to the anastamosis (Figure 1, Top left). Three millilitres of $1 / 10,000$ adrenaline were injected into the bleeding region, with 'blanching' of the mucosa and subsequent cessation of bleeding. The site was then localized and determined to be Dieulafoy's lesion of the rectum (Figure 1, Bottom left). Using a 10 French BICAP probe (bipolar probe, Circon ACMI Corporation, USA) electrocoagulation (20 J, $5 \mathrm{~s}$ intervals, five applications), the lesion was cauterized (Figure 1, Top right, Bottom right). Over the next 12 months, there was no recurrence of bleeding.

\section{DISCUSSION}

'Exulceratio simplex' was a term coined by Dieulafoy (21) to describe a superficial gastric mucosal lesion that he believed to be the initial stages of a gastric ulcer whose progression was interrupted by the occurrence of bleeding. The 'Dieulafoy' lesion has now, however, been characterized histologically as an unusually large artery coursing just beneath the gastric mucosa (22). Once thought to be a rare cause of gastrointestinal hemorrhage, the widespread use of emergency endoscopy has led to increasing numbers of reports of this lesion in various parts of the gastrointestinal tract. Although usually considered an acquired abnormality, a congenital etiology has been suggested by authors who have discovered the lesion in patients as young as 20 weeks old (30). The most common site of these lesions remains the stomach, with most lesions located in the body $(67 \%)$ and a smaller number $(25 \%)$ in the fundus of the stomach (25).

Dieulafoy's lesions of the colon were first reported by Barbier et al (31) in 1985, when three cases of lower gastrointestinal hemorrhage from 'Dieulafoy-like' lesions were published. Since that time, 19 other cases of lower gastrointestinal bleeding from Dieulafoy's lesions have been reported (Table 1). What actually causes these lesions to bleed is a source of speculation. No correlation has been noted with alcohol, smoking, nonsteroidal anti-inflammatory drugs or peptic ulcer disease. Constipation has been suggested as an initiating factor in colonic Dieulafoy's lesions $(27,32,33)$, as has arterial compression of the mucosa (leading to a mucosal erosion) (30).

Of all 22 colonic lesions reported, 11 were located in the right colon, one in the transverse colon and the other 10 in 
the rectum. Seventeen of the 22 lesions were diagnosed by endoscopic means. Similar to Dieulafoy's lesions of the stomach, approximately twice as many men were affected as women (15 versus seven) (34). The mean age was 58 years old. Eight lesions (three rectal, five right colon) were treated surgically (three oversewn, five right hemicolectomies). The other 14 lesions were treated endoscopically with a combination of adrenaline and heater probe $(\mathrm{n}=7)$; heater probe alone $(\mathrm{n}=3)$; adrenaline and yttrium-argon-garnet laser $(\mathrm{n}=1)$; adrenaline and a sclerosing agent $(\mathrm{n}=2)$; and snare polypectomy $(n=1)$. Two patients treated endoscopically subsequently had recurrent bleeding. One had been treated with adrenaline injection, and a repeat endoscopic treatment with a sclerosing agent (alcohol and sodium tetradocyl sulphate) successfully stopped the bleeding (32). Another had a lesion at the hepatic flexure treated initially with heater probe coagulation and adrenaline. Repeat therapy with the same modalities was successful when he rebled three days after the initial treatment (26). One of the lesions treated surgically (oversewn) had previously failed endoscopic therapy (33). The other two rectal lesions were treated surgically (despite successful endoscopic treatment in one) (35), presumably on the assumption that endoscopic therapy would not result in long term success in the cessation of bleeding.

This case of a Dieulafoy's lesion is the 11th discovered in the rectum. All presented with hematochezia. Only two were female (both five years old) (36). Overall, 10 of 11 patients with rectal Dieulafoy's lesions were diagnosed endoscopically (one by nuclear scintigraphy). Three patients subsequently had surgical oversewing performed, but only one of the surgical cases had failed endoscopic management (33). In another, surgical oversewing was performed intraoperatively when the lesion was discovered within the rectum (37). The case presented is the only one treated with bipolar electrocauterization. It is possible that the previous colonic surgery that our patient underwent may have altered blood flow patterns and, theoretically, made a vulnerable vessel more likely to bleed. However, because other patients with Dieulafoy's lesions of the rectum had not had prior surgical intervention of the colon, this theory of etiology is unsupported.

With the advent of therapeutic endoscopy, the management of gastric Dieulafoy's lesions has been altered drastically. In as late as 1986, surgical therapy was considered to be the treatment of choice (34). A host of endoscopic modalites (heater probe, injection sclerotherapy, monopolar electrocoagulation, bipolar electrocoagulation, band ligation, hemoclips [38] and laser photocoagulation) have been used successfully in the therapy of these lesions. Approximately $85 \%$ of patients managed endoscopically have not had any evidence of rebleeding (25). This clearly has defined endoscopic management as the primary modality of therapy in the stomach. Within the colon, however, the diagnosis can be even more challenging. Bright red blood may limit visibility and, as in several cases listed above, has led to 'blind' hemicolectomies. Ideally, the site of bleeding should be localized, and, if possible, endoscopic therapy should be initiated, because in most patients, it is successful. It appears that multiple endoscopic therapies can be successful in treating Dieulafoy's lesions in the colon; surgery should be reserved for those who fail endoscopic therapy. These cases further show that long term success with endoscopic treatment is also expected and that surgical intervention is usually not required.

\section{REFERENCES}

1. Boley SJ, Sammartano R, Adams A, et al. On the nature and etiology of vascular ectasias of the colon. Degenerative lesions of aging. Gastroenterology 1977;72:650-60.

2. Berner JS, Mauer K, Lewis BS. Push and sonde enteroscopy for the diagnosis of obscure gastrointestinal bleeding. Am J Gastroenterol 1994;89:2139-42.

3. Howard TJ, Plaskon LA, Wiebke EA, et al. Nonocclusive mesenteric ischemia remains a diagnostic dilemma. Am J Surg 1996;171:405-8.

4. Lewis BS, Kornbluth A, Waye JD. Small bowel tumours: yield of enteroscopy. Gut 1991;32:763-5.

5. Milewski PJ, Schofield PF. Massive colonic haemorrhage - the case for right hemicolectomy. Ann R Coll Surg Engl 1989;71:253-9.

6. Vernava AM, Moore BA, Longo, et al. Lower gastrointestinal bleeding. Dis Colon Rectum 1997;40:846-58.

7. Vernava AM, Longo WE, Virgo KS, et al. A nationwide study of the incidence and etiology of lower gastrointestinal bleeding. Surg Res Commun 1996;18:113-20.

8. Jensen DM, Machicado GA. Diagnosis and treatment of severe hematochezia. The role of urgent colonoscopy after purge. Gastroenterology 1988;95:1569-74.

9. Rosen AM, Fleischer DE. Upper GI bleeding in the elderly: diagnosis and management. Geriatrics 1933;44:26-8.

10. Caos A, Benner KG, Manier J, et al. Colonoscopy after Golytely preparation in acute rectal bleeding. J Clin Gastroenterol 1986;8:46-9.

11. Heer M, Ammann R, Buhler H. [Clinical significance of colonic angiodysplasias]. Schweiz Med Wochenschr 1984;114:1416-22.

12. Leitman IM, Paull DE, Shires GT. Evaluation and management of massive lower gastrointestinal hemorrhage. Ann Surg 1989;209:175-80.

13. Rossini FP, Ferrari A, Spandre M, et al. Emergency colonoscopy. World J Surg 1989;13:190-2.

14. Boley SJ, DiBiase A, Brandt LJ, Sammartano RJ. Lower intestinal bleeding in the elderly. Am J Surg 1979;137:57-64.

15. Wright HK. Massive colonic hemorrhage. Surg Clin North Am 1980;60:1297-304.

16. Baum S, Athanasoulis CA, Waltman AC. Angiographic diagnosis and control of large-bowel bleeding. Dis Colon Rectum 1974; $17: 447-53$.

17. Colacchio TA, Forde KA, Patsos TJ, et al. Impact of modern diagnostic methods on the management of active rectal bleeding. Ten year experience. Am J Surg 1982;143:607-10.

18. Forde KA. Colonoscopy in acute rectal bleeding. Gastrointest Endosc $1981 ; 27: 219-20$

19. Jensen DM, Machicado GA. Colonoscopy for diagnosis and treatment of severe lower gastrointestinal bleeding. Routine outcomes and cost analysis. Gastrointest Endosc Clin North Am 1997;7:477-98.

20. Gallard T. Aneurysmes miliaires de l'estomac donnant lieu a des hematemeses montelles. Bull Soc Med Paris 1884;1:84-91.

21. Dieulafoy G. Exulceratio simplex. L'intervention chirurgicale dans les hematemeses foudroyantes consecutives a l'exulceration simplex de l'estomac. Bull Acad Med 1889;39:49-84.

22. Juler GL, Labitzke HG, Lamb R, et al. The pathogenesis of Dieulafoy's gastric erosion. Am J Gastroenterol 1984;79:195-200.

23. Jaspersen D, Korner T, Schorr W, et al. Extragastric Dieulafoy's disease as unusual source of intestinal bleeding. Esophageal visible vessel. Dig Dis Sci 1994;39:2558-60.

24. Pointner R, Schwab G, Konigsrainer A, et al. Endoscopic treatment of Dieulafoy's disease. Gastroenterology 1988;94:563-6.

25. Reilly HF, al-Kawas FH. Dieulafoy's lesion. Diagnosis and management. Dig Dis Sci 1991;36:1702-7.

26. Dy NM, Gostout CJ, Balm RK. Bleeding from the endoscopicallyidentified Dieulafoy lesion of the proximal small intestine and colon. Am J Gastroenterol 1995;90:108-11. 
27. Meister T, Varilek G, Marsanao, et al. Endoscopic management of rectal Dieulafoy-like lesions: A case series and review of the literature. Gastrointest Endosc 1998;48:302-4.

28. Gadenstatter M, Wetscher G, Crookes PF, et al. Dieulafoy's disease of the large and small bowel. J Clin Gastroenterol 1998;27:169-72.

29. Goins WA, Chatman DM, Kaviani MJ. Massive lower gastrointestinal bleeding due to 'Dieulafoy's vascular malformation' of the jejunum: case report. J Natl Med Assoc 1995;87:766-70.

30. Rossi NP, Green EW, Pike JD. Massive bleeding of the upper gastrointestinal tract due to Dieulafoy's erosion. Arch Surg 1968;97:797-800.

31. Barbier P, Luder P, Triller J, et al. Colonic hemorrhage from a solitary minute ulcer. Report of three cases. Gastroenterology 1985;88:1065-8.

32. Abdulian JD, Santoro MJ, Chen YK, Collen MJ. Dieulafoy-like lesion of the rectum presenting with exsanguinating hemorrhage: successful endoscopic sclerotherapy. Am J Gastroenterol 1993;88:1939-41.

33. Franko E, Chadavoyne R. Massive rectal bleeding from a Dieulafoy's type ulcer of the rectum: a review of this unusual disease. Am J Gastroenterol 1991;88:1939-41.

34. Veldhuyzen ZS, Bartelsman JF, Schipper ME, Tytgat GN. Recurrent massive haematemesis from Dieulafoy vascular malformations - a review of 101 cases. Gut 1986;27:213-22.
35. Abdelmalek MF, Pockaj BA, Leighton JA. Rectal bleeding from a mucous fistula secondary to a Dieulafoy's lesion. J Clin Gastroenterol 1997;24:259-61

36. Tooson JD, Marsano LS, Gates LK Jr. Pediatric rectal Dieulafoy's lesion. Am J Gastroenterol 1995;90:2232-3.

37. Eguchi S, Maeda J, Taguchi H, et al. Massive gastrointestinal bleeding from a Dieulafoy-like lesion of the rectum. J Clin Gastroenterol 1997;24:262-3.

38. Parra-Blanco A, Takahashi H, Mendez JP, et al. Endoscopic management of Dieulafoy lesions of the stomach: a case study of 26 patients. Endoscopy 1997;29:834-9.

39. Richards WO, Grove-Mahoney D, Williams LF. Hemorrhage from a Dieulafoy type ulcer of the colon: a new cause of lower gastrointestinal bleeding. Am Surg 1988;54:121-4.

40. Schmitt W, Lux G, Giedl J. Colonic haemorrhage from solitary submucosal vessels diagnosed by lower gastrointestinal Dopplerendoscopy. Endoscopy 1987;19:43-5.

41. Schmid K, Pointner R, Feichtinger J. Exulceratio simplex Dieulafoy of the colon - A case report. Endoscopy 1988;20:88-9.

42. Ma CK, Padda H, Pace EH, Szilagyi E. Submucosal arterial malformation of the colon with massive hemorrhage. Report of a case. Dis Colon Rectum 1989:32:149-52. 


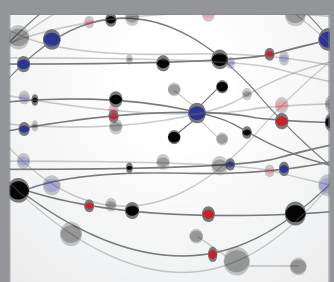

The Scientific World Journal
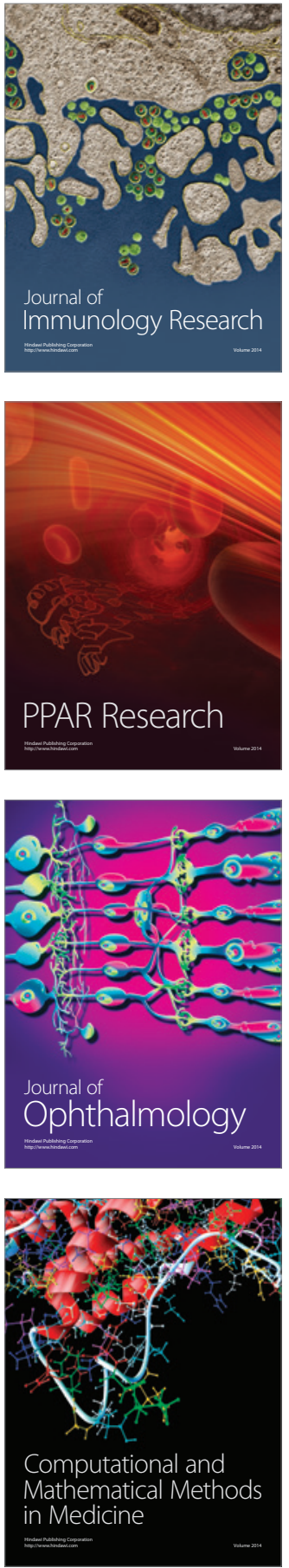

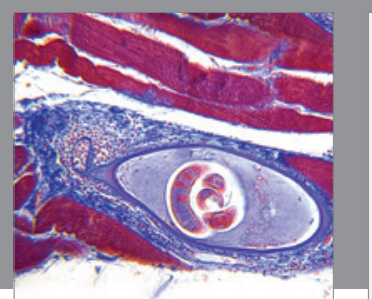

Gastroenterology Research and Practice

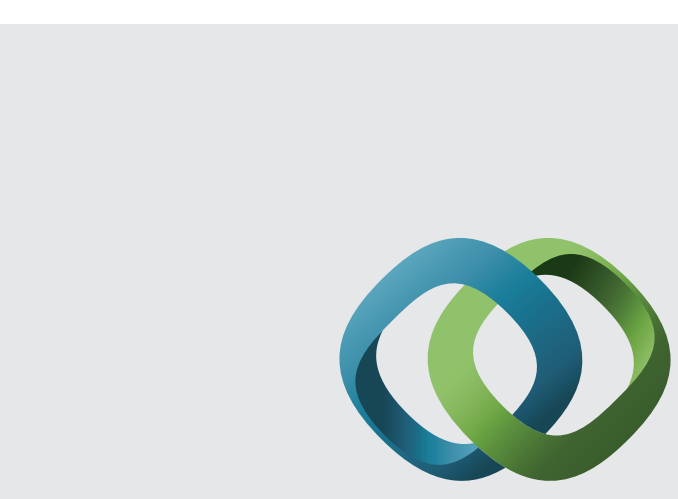

\section{Hindawi}

Submit your manuscripts at

http://www.hindawi.com
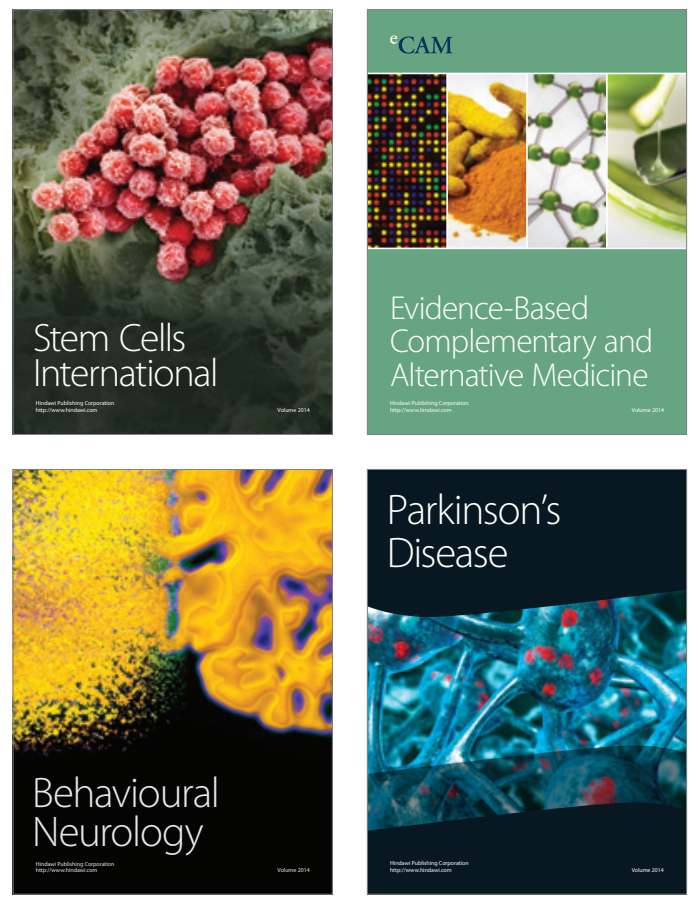
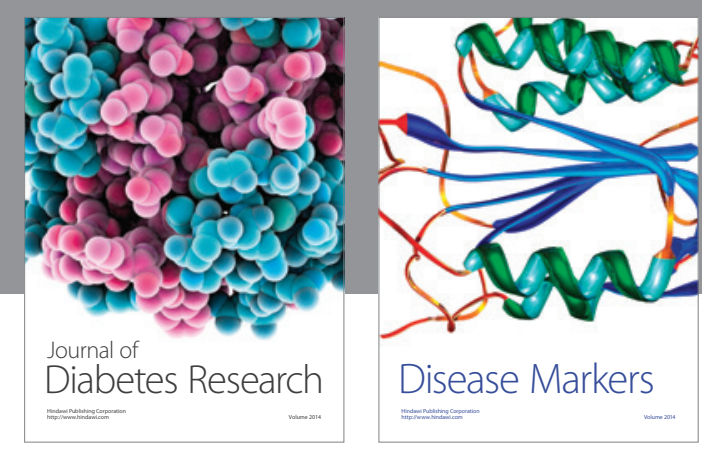

Disease Markers
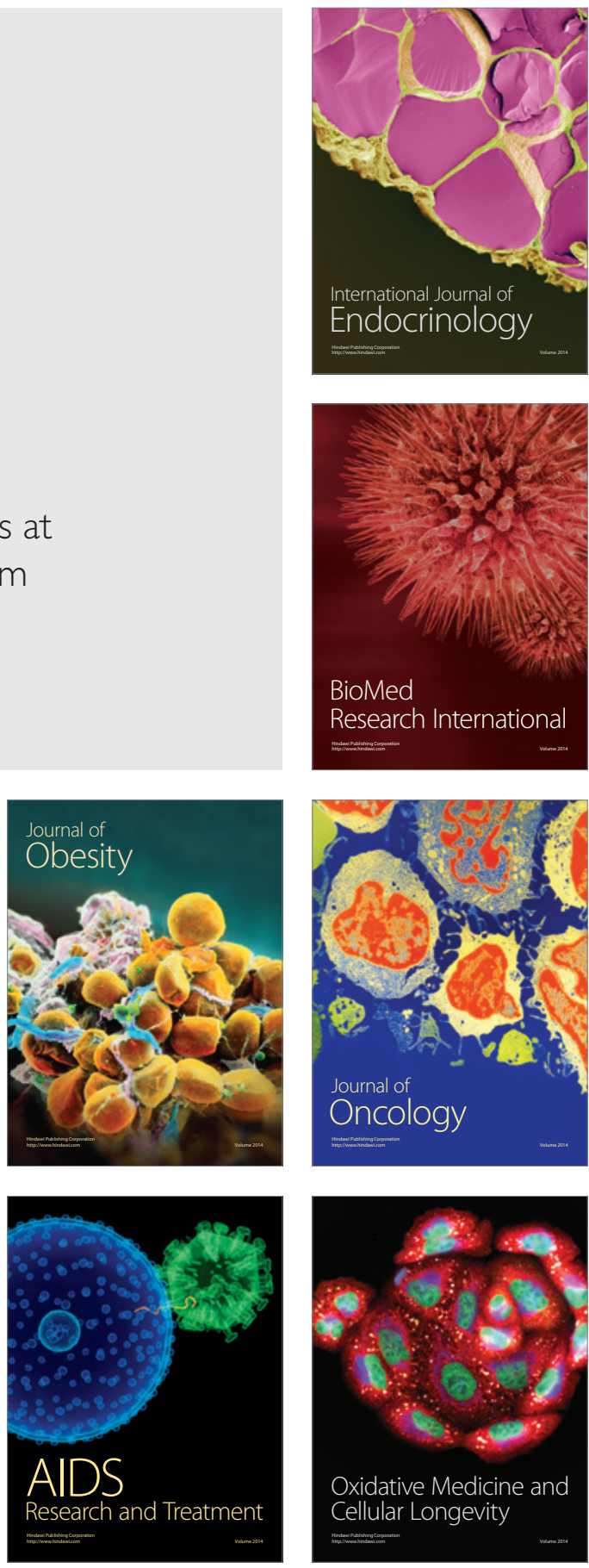